Article

\title{
Enhanced Mechanical Properties of Carbon Nanotube/Aluminum Composites Fabricated by Powder Metallurgical and Repeated Hot-Rolling Techniques
}

\author{
Hideaki Tsukamoto \\ Department of Mechanical Engineering, Faculty of Science and Engineering, Hosei University, 3-7-2 Kajino-cho, \\ Koganei, Tokyo 184-8584, Japan; htsukamoto@hosei.ac.jp
}

Received: 4 November 2020; Accepted: 19 November 2020; Published: 20 November 2020

\begin{abstract}
This research aimed to fabricate lightweight and high-strength carbon nanotube $(\mathrm{CNT})$ /aluminum (Al) composites by powder metallurgical and repeated hot-rolling techniques. The fabrication was conducted in three steps: (1) CNT dispersion, (2) preparation of CNT/Al compacts by powder metallurgical slurry methods, and (3) strengthening and refining of CNT/Al composites by repeated hot rolling. The processes of dispersion of CNTs were carried out with dimethylacetamide as a solvent and potassium carbonate as a dispersing agent, which is an inorganic salt, under ultrasonic sonication conditions. Effect of sonication time on dispersion states and mechanical properties was also examined.
\end{abstract}

Keywords: carbon nanotube; aluminum matrix composites; powder metallurgy; repeated hot rolling; mechanical property

\section{Introduction}

Recently, in order to cope with environmental issues such as $\mathrm{CO}_{2}$ emissions reduction, replacing various structural materials like heavy metals such as iron $(\mathrm{Fe})$ materials, comprising the major parts in automobiles, buildings, bridges, etc., with light metals such as aluminum $(\mathrm{Al})$, magnesium $(\mathrm{Mg})$, and titanium (Ti) has been highly desirable. However, the weight reduction of structural materials by light metals often leads to a decrease in strength, which causes problems related to safety and sustainability [1,2].

Carbon nanotubes (CNTs) have received broad scientific and industrial attention in the past decades due to their excellent physical and chemical properties such as high elastic modulus, high strength, high thermal conductivity, low density, and so on. CNTs are tube-like materials with a diameter of a nanometer scale, which is made up of carbon. Depending on the number of carbon layers, CNTs can be classified into two categories: single-walled carbon nanotubes (SWCNTs) and multi-walled carbon nanotubes (MWCNTs). Due to these interesting properties, CNTs can play a significant role in the fields of nanotechnology, electronics, optics, and materials science [2-4]. CNTs have been regarded as a powerful candidate for the reinforcement of metal matrix composites (MMCs) [5,6].

Attempts to develop CNT/Al matrix composites with enhanced strength are highly attractive, as they can be suitable structural materials in aerospace and automobile industries. However, at present, there are very few practical examples due to the difficulty in obtaining uniform dispersion and wetting of CNTs with the matrix. Most bulk CNT/Al composites exhibit poorer mechanical properties than expected. Many efforts have been made to prepare such CNT/metal composites with homogeneous distribution as well as high volume fraction of CNT simultaneously. Namely, the processing difficulty is represented by the uniform dispersion of the reinforcements into the matrix 
without damaging the nanotubes. To achieve this issue, chemical and mechanical treatments have mainly been conducted [5-7].

CNTs can be subject to some surface treatment to improve dispersion and wetting, which is a kind of chemical treatment. It has been reported that there is a possibility that properties of CNT may be impaired by surface treatments. The processing difficulty is represented by the uniform dispersion of the reinforcements into the matrix without damaging the nanotubes [8]. It was also proposed that in order not to reduce the advantage in the properties of CNT, dimethylacetamide as a solvent and potassium carbonate, which is an inorganic salt, acting as a dispersing agent, were used for dispersion under sonication treatments [9].

Mechanical treatments also contribute to improving the dispersibility of CNTs in MMCs. Uniform dispersion of CNT can be improved by plastic deformation after powder metallurgical processing. The post-processing could improve the interfacial bonding through the elimination of the residual pores and voids, enhancement of metal-CNT interfacial bonding, breakage of CNT clusters, and strengthening the alignment of CNTs [10]. It is considered that porosity in the composites can degrade mechanical properties, so it is effective to strengthen the interfacial bonding and enhance the densification by post-processing. Some researchers [11-13] have reported that hot extrusion and equal channel angular pressing (ECAP) were useful post-sintering processes to enhance the bonding strength between $\mathrm{Al}$ powders and improve dispersibility of the CNTs in Al matrix. Hot rolling can also be a candidate for this purpose to obtain flat or plate-shape samples [10].

In this study, high-performance lightweight CNT/Al-based composites were fabricated by combining powder metallurgy and repeated hot-rolling techniques. Dimethylacetamide as a solvent and potassium carbonate, which is an inorganic salt, as a dispersing agent can be used to reduce agglomeration of CNTs to bring out the inherent ability of CNTs in the composites. Microstructures and mechanical properties were investigated through scanning electron microscope (SEM) observations, micro Vickers hardness, and tensile tests to be related to the fabrication processes.

\section{Experiments}

\subsection{Fabrication}

$\mathrm{Al}$ powder with a particle size of $30 \mu \mathrm{m}$ and purity of $99.8 \%$ (supplied by Nilaco Co. Ltd., Nilaco Bldg., 1-20-6 Ginza, Chuo-ku, Tokyo 104-0061, Japan) and MWCNTs with a diameter of 10-15 nm and an aspect ratio of 1000 (supplied by CNano Technology Co. Ltd. through Marubeni Information Systems (MSYS) Co. Ltd., Shinjuku Garden Tower, 3-8-2, Okubo, Shinjuku-ku, Tokyo 169-0072, Japan) were mixed. Potassium carbonate was used as the dispersant, and dimethylacetamide was used as the solvent. The CNT powder and potassium carbonate were put together into dimethylacetamide, followed by sonication using ultrasonic equipment. Figure 1 shows a schematic illustration of the CNT dispersion process. The mixture was filtered using filter paper, and the CNT powder was taken out. A mixed powder was prepared from the CNT powder and Al powder, poured into a mold, and dried using a heat gun. After that, compression molding was performed at $150 \mathrm{kPa}$ using a press machine. Then, it was sintered at $500{ }^{\circ} \mathrm{C}$ for $2 \mathrm{~h}$ in an electric furnace.

\subsection{Hot Rolling}

The sintered pieces were heated in an electric furnace at $400{ }^{\circ} \mathrm{C}$ for $15 \mathrm{~min}$, and repeated hot rolling was performed with a reduction ratio of $3 \%$ for one rolling at the beginning. After rolling ten times, the reduction ratio was changed from 4 to $5 \%$ for one rolling. Then, the rolling was repeatedly conducted to a total reduction ratio of $30 \%$. Figure 2 shows the repeated processes of hot rolling. 


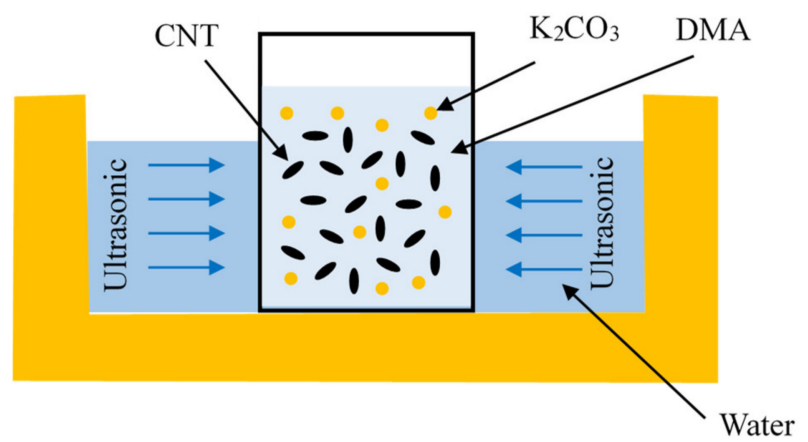

Figure 1. Schematic illustration of the carbon nanotube (CNT) dispersion process.

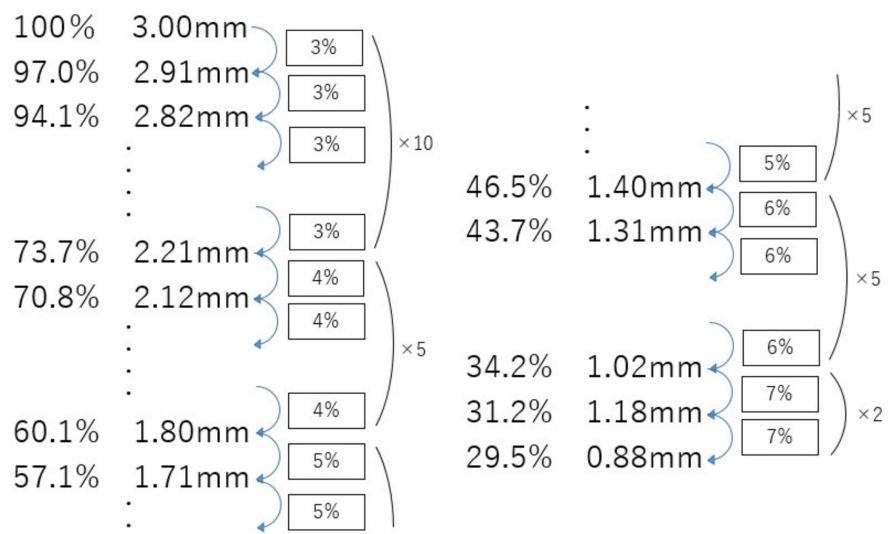

Figure 2. Repeated hot-rolling processes.

\subsection{Characterization}

After preparation of the composite materials, evaluation of the dispersibility of CNTs in the composites, Vickers hardness test, three-point bending test, and tensile test were carried out. Cross-sectional observation of the CNT/Al composites carried out with a scanning electron microscope (SEM, SU8020, Hitachi High-Tech Co. Ltd., Toranomon Hills Business Tower, 1-17-1 Toranomon, Minato-ku, Tokyo 105-6409, Japan) and energy dispersive x-ray spectrometry (EDX). For Vickers hardness test, the cross section of the test piece was polished, and the Vickers hardness test (at five points) was performed. For three-point bending tests, the test pieces were prepared by cutting the outside edges from rolled samples. Displacement rate was $1.0 \mathrm{~mm} / \mathrm{min}$. The support span was $25 \mathrm{~mm}$. For tensile tests, Instron-type tensile equipment was used, and the strain rate was set at $5.6 \times 10^{-6} / \mathrm{s}$. Elastic modulus, tensile strength, maximum strain could be estimated and anisotropy also examined.

\section{Results}

The SEM backscattered electron image and EDX mapping results for the cross section of 1.0 mass. $\%$. $\mathrm{CNT} / \mathrm{Al}$ composites with an ultrasonic treatment of $1 \mathrm{~h}$ are shown in Figure 3. Cylinder-like aggregation of CNT can be seen with the length of more than $100 \mu \mathrm{m}$. Figure 4 shows the cross-sectional SEM images for the CNT/Al composites, which covered CNT contents of 0.5, 1.0, and 2.0 mass.\%. and ultrasonic treatment time of 1,3 , and $5 \mathrm{~h}$.

It can be seen that the CNTs were relatively uniformly dispersed, even though some aggregations of CNT could be observed.

Next, we focused on estimating the CNT dispersion states. CNT dispersion states are represented by the combination of the length and number of CNT aggregations. Length and number of CNT aggregations were measured in the cross-section area of $1 \mathrm{~mm}^{2}$. Figure 5 shows the influence of sonication time on CNT dispersion states for 1.0 mass.\% CNT composites. It can be seen in Figure 5 that with increasing sonication time, the number of CNT aggregation decreased, in particular, long CNT aggregation significantly decreased. 


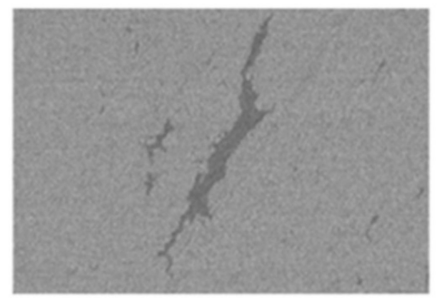

$100 \mu \mathrm{m}$

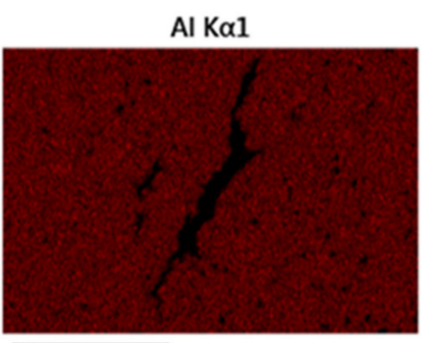

$100 \mu \mathrm{m}$

(a)

(b)

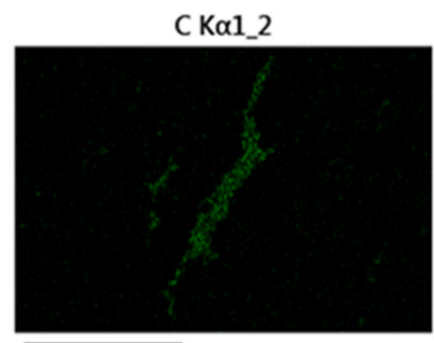

$100 \mu \mathrm{m}$

(c)

Figure 3. Cross-sectional scanning electron microscope (SEM) image (a) and energy dispersive x-ray spectrometry (EDX) mapping results $(\mathrm{Al}(\mathbf{b})$ and $\mathrm{C}(\mathbf{c}))$ focusing on CNT aggregation in CNT/Al composites (ultrasonic treatment for $1 \mathrm{~h}, \mathrm{CNT}$ content of 1.0 mass.\%).

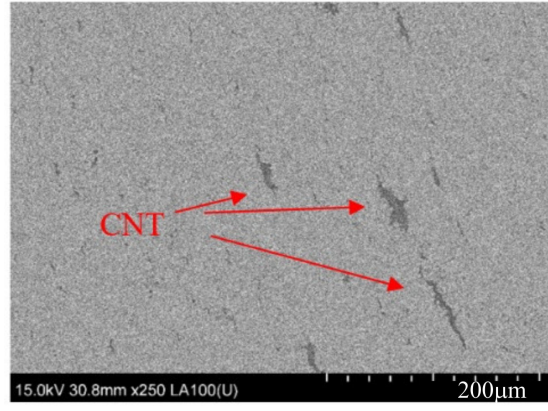

(a)

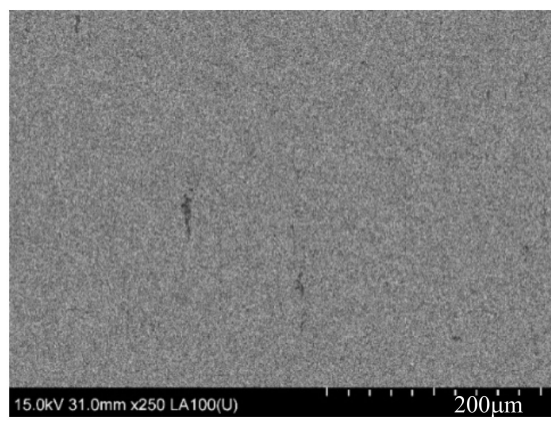

(c)

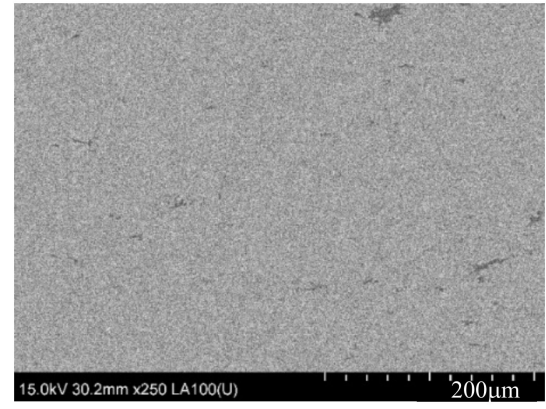

(b)

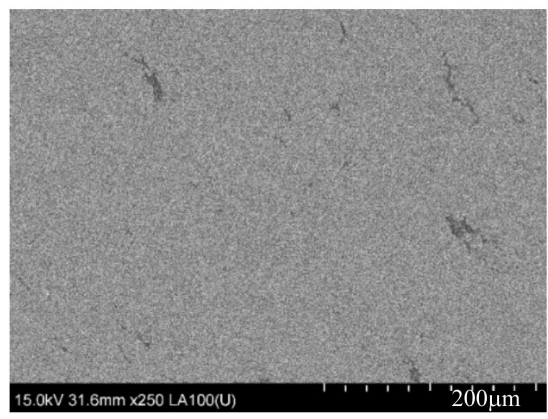

(d)

Figure 4. Cross-sectional SEM images for CNT/Al composites. CNT contents were 1.0 mass.\% (a); 1.0 mass.\% (b); 0.5 mass.\% (c); and 2.0 mass.\% (d). Ultrasonic treatment time was $1 \mathrm{~h} \mathrm{(a);} 5$ h (b); 3 h (c); and $3 \mathrm{~h}(\mathbf{d})$.

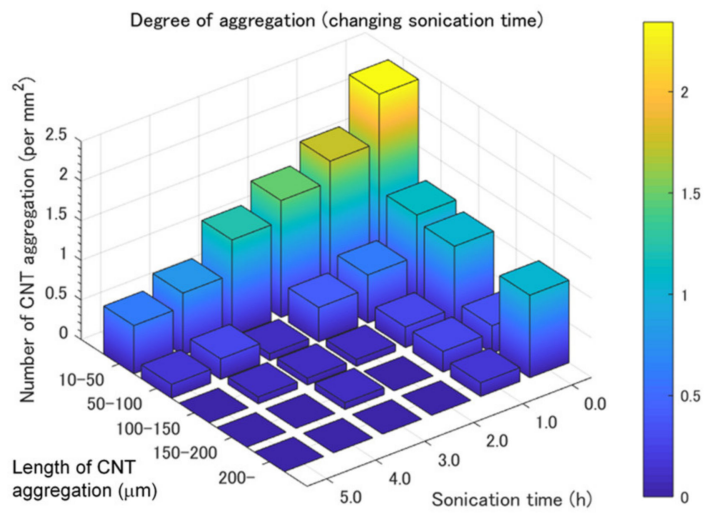

Figure 5. Influence of sonication time on CNT dispersion states (1.0 mass.\% CNT/Al composites). 
Figure 6 shows the influence of CNT content on CNT dispersion states for a sonication time of $3 \mathrm{~h}$. It can be seen in Figure 6 that with decreasing CNT content, the number of CNT aggregation decreased, for most of the length of the CNT aggregations.

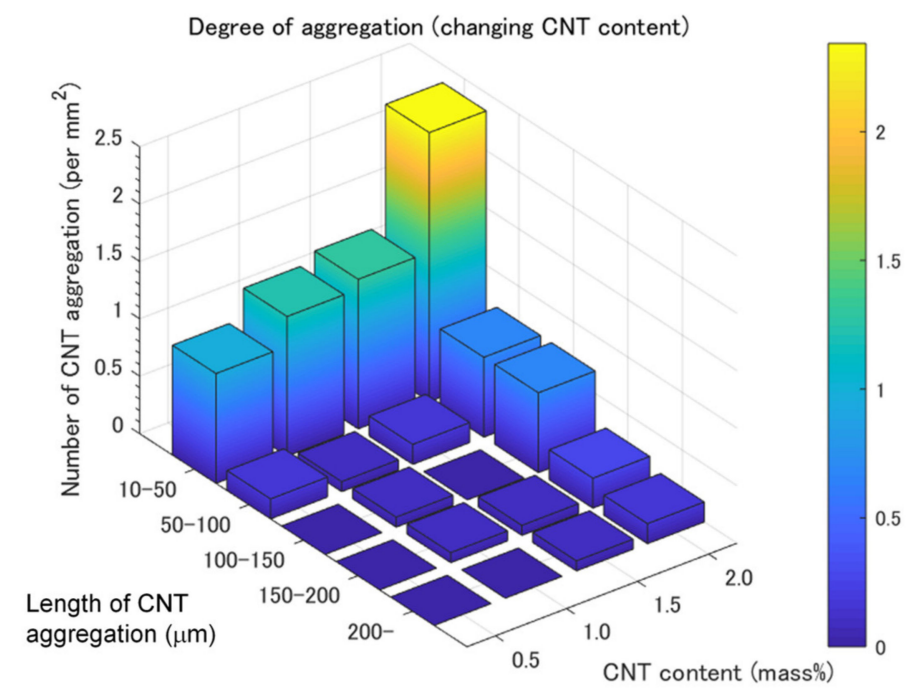

Figure 6. Influence of CNT content on CNT dispersion states (sonication time of $3 \mathrm{~h}$ ).

The photos of the test pieces before and after repeated hot rolling are shown in Figure 7. It can be seen that the edge parts had rolling cracks, which were cut off for making bending and tensile test pieces.

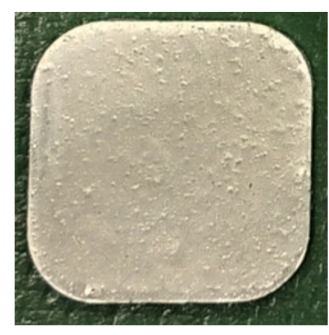

(a)

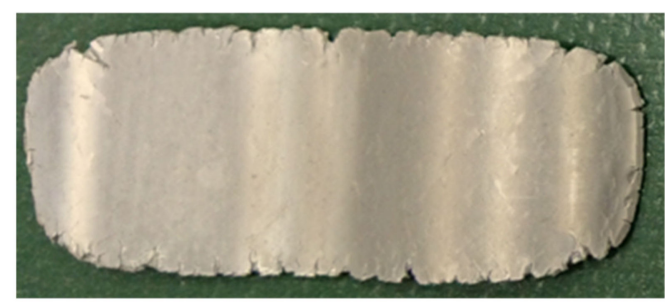

(b)

Figure 7. Sample photos: (a) before and (b) after repeated hot rolling.

Figure 8 shows the relationship between bending stress and strain (at the top surface of test pieces) derived from three-point bending load and displacement for a sonication time of 0,3 , and $4 \mathrm{~h}$ for 0.5 mass. \% CNT/Al composites. Elastic analysis was applied to the whole deformation. It can be seen that the samples at a sonication time of $0 \mathrm{~h}$ and $4 \mathrm{~h}$ showed large deformation, but there was not as much difference in the maximum bending strength among the samples.

Figure 9 shows the relationship between flexural modulus and sonication time for $\mathrm{Al}$ and 0.5 mass.\% CNT/Al composites. It was confirmed that the flexural modulus increased with sonication time up to a sonication time of $3 \mathrm{~h}$. In the case of $4 \mathrm{~h}$, the value dropped sharply, which was almost the same as the value for $0 \mathrm{~h}$. The reason for the low value of the flexural modulus at $0 \mathrm{~h}$ was due to the least dispersion of CNTs, that is, CNTs aggregated and formed into lumps. 


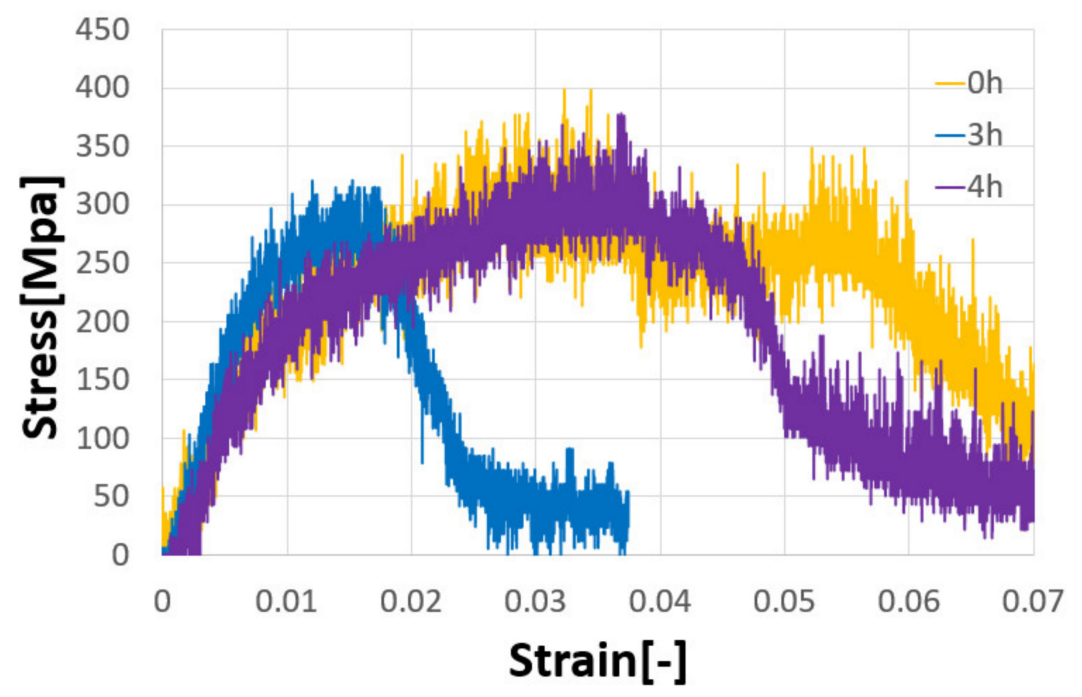

Figure 8. Stress-strain diagrams for 0.5 mass. $\% \mathrm{CNT} / \mathrm{Al}$ composites from the three-point bending tests.

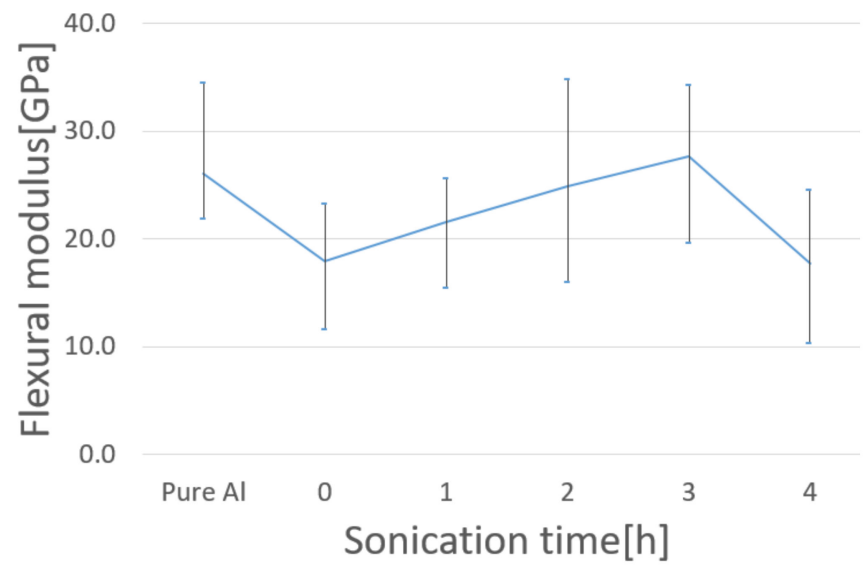

Figure 9. Flexural modulus as a function of sonication time for $\mathrm{Al}$ and 0.5 mass. $\% \mathrm{CNT} / \mathrm{Al}$ composites.

Next, we move to the results of the tensile test. Figure 10 shows the stress-strain curves for pure $\mathrm{Al}$ and 0.5 mass.\% CNT/Al composites for sonication times of $0,1,2,3$, and $4 \mathrm{~h}$. For elongation, compared with $\mathrm{Al}$, the 0.5 mass.\% CNT/Al composites with a sonication time of 3 and $4 \mathrm{~h}$ showed similar or larger elongation.

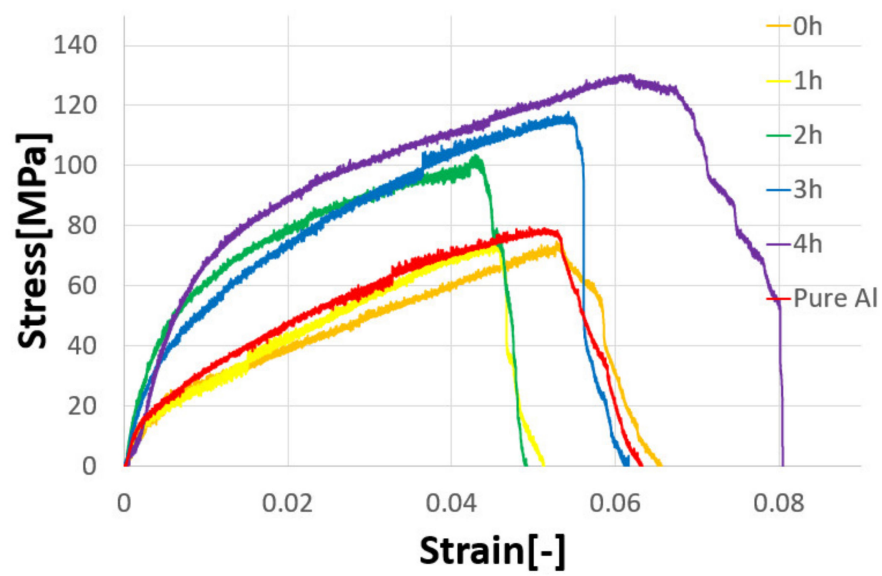

Figure 10. Stress-strain curves for $\mathrm{Al}$ and 0.5 mass.\% CNT/Al composites. 
Figure 11 shows the Young's modulus and tensile strength as a function of sonication time for the $\mathrm{Al}$ and 0.5 mass.\% CNT/Al composites.

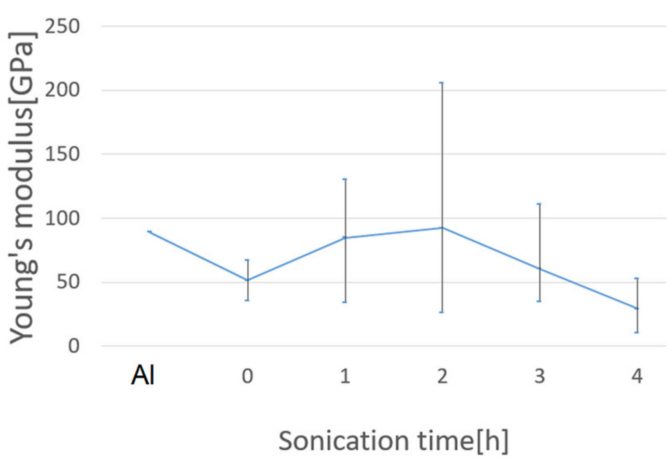

(a)

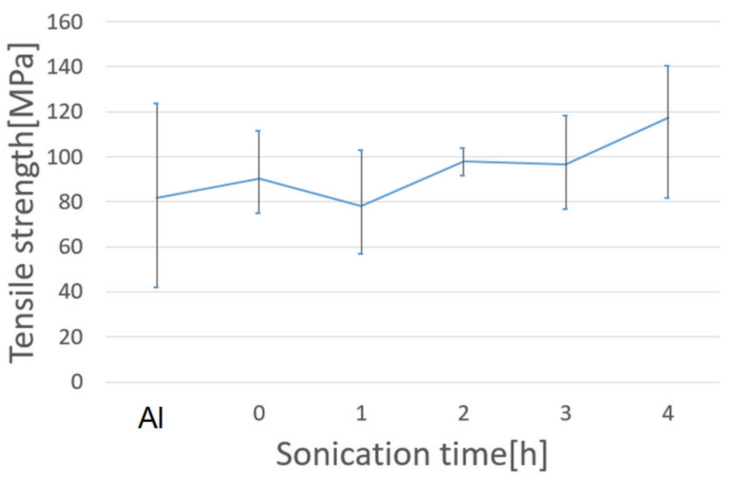

(b)

Figure 11. Young's modulus (a) and tensile strength (b) as a function of sonication time for the $\mathrm{Al}$ and 0.5 mass.\% CNT/Al composites.

The Young's modulus of pure $\mathrm{Al}$ is around $90 \mathrm{GPa}$, and the average values of Young's modulus of the composites were between 30 and $92 \mathrm{GPa}$. Maximum value was achieved for the composites with a sonication time of $2 \mathrm{~h}$, and the minimum for the composites with a sonication time of $4 \mathrm{~h}$. There can be a high value of Young's modulus for the composites with a sonication time of 2 h. For tensile strength, with an increase in sonication time, tensile strength tended to increase. The composites with a sonication time of $4 \mathrm{~h}$ showed the highest value of tensile strength. It can also be seen in Figure 10 that the composites with a sonication time of $4 \mathrm{~h}$ showed the highest tensile strength as well as the highest deformation ability.

Figure 12 shows the Vickers hardness test results. The CNT content of the composites was 0.5 mass.\%. The literature value of the Vickers hardness of pure Al (1000 series) is around 30 (HV). In this study, the rolled Al showed a hardness of more than four times. This is because work hardening occurs with plastic deformation by rolling. It was also seen that the influence of sonication time was not that high, and containing CNTs did not have much of an effect on Vickers hardness.

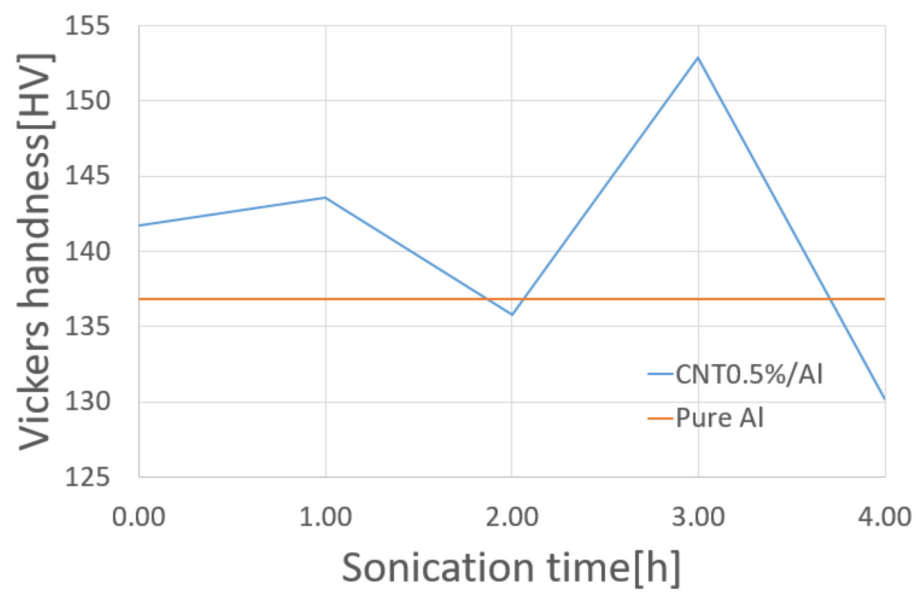

Figure 12. Relationship between Vickers hardness and sonication time.

\section{Discussion}

In this study, chemical treatments were carried out to disperse CNTs in an Al matrix. Dimethylacetamide was used as a solvent and potassium carbonate, which is an inorganic salt, was used as a dispersing agent. Ultrasonic sonication was conducted for the slurry-like mixture of $\mathrm{CNT}$ and Al powders. The process of sonication is very important to make CNTs uniformly dispersed. 
Sonication time highly affects the dispersibility of CNTs in an $\mathrm{Al}$ matrix. It was shown in Figure 5, that with increasing sonication time, the amount of CNT aggregation decreased, particularly, long CNT aggregation decreased in the case of a sonication time longer than $2 \mathrm{~h}$. Even though this result was prior to repeated hot rolling, a similar tendency in the relationship between the dispersibility of CNTs and sonication time can expected to be confirmed after repeated hot-rolling samples. It can be considered that the mechanical properties of the composites after repeated hot-rolling can be experimentally connected to sonication time, as shown in Figures 8-12, which are possibly also connected to the dispersibility of CNTs in Figure 5.

From Figure 5, Figure 9, and Figure 11a, the flexural modulus and (tensile) Young's modulus increased to some extent with increasing sonication time up to 2 or $3 \mathrm{~h}$, then decreased. This may be due to the effect caused by a combination of states of aggregation of CNTs and rolling. Even so, flexural and Young's moduli were not so much affected by sonication time, which means that the dispersibility of CNTs did not have much influence on these moduli.

Meanwhile, from Figures 5 and 11b, with increasing sonication time, which led to higher dispersibility of CNTs, the tensile strength of the composites after repeated hot rolling increased. Repeated hot-rolling processes can also facilitate the increase in the tensile strength of the composites. As described in the Introduction, it is considered that post-sintering processing improves bonding strength between $\mathrm{Al}$ powders and CNTs, and the dispersion uniformity of CNTs in an Al matrix. The enhanced strength of the nanocomposites can be attributed to the stronger diffusional bonds and homogeneous distribution of CNTs in the Al matrix. It has been reported that homogenously distributed CNTs in an Al matrix can act as reinforcements to effectively prevent dislocation movement [10].

It can be seen in Figure 10 (tensile stress-strain curves) that the composites with sonication time of $4 \mathrm{~h}$ showed the largest elongation in the tensile test samples. This result is of much interest because some literature has reported that higher CNT content leads to lower toughness and lower ductility of the composites [10]. It is considered that plastic deformation such as rolling, extrusion, and drawing forms a strong texture, while hot rolling possibly causes dynamic recovery and recrystallization in such composites. Repeated hot rolling processes may contribute to higher tensile strength as well as high deformability of the composites.

\section{Conclusions}

$\mathrm{CNT} / \mathrm{Al}$ composites were fabricated by combining powder metallurgy and repeated hot rolling techniques. Fabrication processes, microstructures including dispersibility of CNTs, and mechanical properties were examined. The following summary was obtained.

1. Chemical treatments using potassium carbonate as the dispersant and dimethylacetamide as the solvent followed by ultrasonic sonication were effective at avoiding agglomeration of CNTs and uniformly dispersed the CNTs in the Al matrix.

2. The sonication time had a great influence on the dispersing state of CNTs. With increasing sonication time, the amount of CNT aggregation decreased.

3. Vickers hardness of the composites was not particularly influenced by sonication time and CNT content.

4. It was demonstrated from the three-point bending test that flexural modulus increased with sonication time increasing up to $3 \mathrm{~h}$.

5. It was demonstrated from the tensile test that with increasing sonication time, which led to higher dispersibility of the CNTs, the tensile strength of the composites after repeated hot rolling increased. The composites with a sonication time of $4 \mathrm{~h}$ (longest one in the current study) showed the highest tensile strength as well as the highest deformation ability.

Funding: This research received no external funding.

Conflicts of Interest: The authors declare no conflict of interest. 


\section{References}

1. Mohapatra, J.; Nayak, S.; Mahapatra, M.M. Mechanical and tribology properties of Al-4.5\%Cu-5\%TiC metal matrix composites for light-weight structures. Int. J. Lightweight Mater. Manuf. 2020, 3, 120-126.

2. Billah, M.M.; Chen, Q. Al-CNT-Ni composite with significantly increased strength and hardness. SN Appl. Sci. 2019, 1, 521. [CrossRef]

3. Anzar, N.; Hasan, R.; Tyagi, M.; Yadav, N.; Narang, J. Carbon nanotube-A review on synthesis, properties and plethora of applications in the field of biomedical science. Sens. Int. 2020, 1, 100003.

4. Agboola, A.E.; Pike, R.W.; Hertwig, T.A.; Lou, H.H. Conceptual design of carbon nanotube processes. Clean Technol. Environ. Policy 2007, 9, 289-311.

5. Hanizam, H.; Sallehc, M.S.; Omar, M.Z.; Sulong, A.B. Optimisation of mechanical stir casting parameters for fabrication of carbon nanotubes-aluminium alloy composite through Taguchi method. J. Mater. Res. Technol. 2019, 8, 2223-2231.

6. Yi, C.; Chen, X.; Gou, F.; Dmuchowski, C.M.; Sharma, A.; Park, C.; Ke, C. Direct measurements of the mechanical strength of carbon nanotube-aluminum interfaces. Carbon 2017, 125, 93-102.

7. Cavaliere, P.; Sadeghi, B.; Shabani, A. Carbon nanotube reinforced aluminum matrix composites produced by spark plasma sintering. J. Mater. Sci. 2017, 52, 8618-8629.

8. Liu, Y.; Geng, C.; Zhu, Y.; Peng, J.; Xu, J. Hot deformation behavior and intrinsic workability of carbon nanotube-aluminum reinforced ZA27 composites. J. Mater. Eng. Perform. 2017, 26, 1967-1977.

9. Matsumoto, K.; Takahashi, T.; Ishii, S.; Jikei, M. Investigation of dispersibility of multi-walled carbon nanotubes using polysulfones with various structures. Int. J. Soc. Mater. Eng. Resour. 2014, 20, 77-81.

10. Sadeghi, B.; Cavaliere, P.; Roeen, G.A.; Nosko, M.; Shamanian, M.; Trembošová, V.; Nagy, Š.; Ebrahimzadeh, N. Hot rolling of MWCNTs reinforced Al matrix composites produced via spark plasma sintering. Adv. Compos. Hybrid Mater. 2019, 2, 549-570.

11. Chen, B.; Kondoh, K.; Imai, H.; Umeda, J.; Takahashi, M. Simultaneously enhancing strength and ductility of carbon nanotube/aluminum composites by improving bonding conditions. SCR Mater. 2016, 113, 158-162.

12. Won, H.; Estili, M.; Takagi, K.; Miyazaki, T.; Kawasaki, A. Combination of hot extrusion and spark plasma sintering for producing carbon nanotube reinforced aluminum matrix composites. Carbon 2009, 47, 570-577.

13. Zare, H.; Jahedi, M.; Toroghinejad, M.R.; Meratian, M.; Knezevic, M. Microstructure and mechanical properties of carbon nanotubes reinforced aluminum matrix composites synthesized via equal-channel angular pressing. Mater. Sci. Eng. A 2016, 670, 205-216.

Publisher's Note: MDPI stays neutral with regard to jurisdictional claims in published maps and institutional affiliations.

(C) 2020 by the author. Licensee MDPI, Basel, Switzerland. This article is an open access article distributed under the terms and conditions of the Creative Commons Attribution (CC BY) license (http://creativecommons.org/licenses/by/4.0/). 